\title{
Community indicators provide an "early warning system" and measure progress of sustainability initiatives
}

\author{
S. Conway ${ }^{1}$, I. Navis ${ }^{2} \&$ A. Wadhwa ${ }^{1}$ \\ ${ }^{1}$ Urban Environmental Research, LLC, USA \\ ${ }^{2}$ Clark County, USA
}

\begin{abstract}
This paper discusses the evolution of the Clark County, Nevada Monitoring Program. This monitoring program is a community indicator system originally designed and implemented in 2005 to establish a baseline, monitor changes over time, and provide an "early warning system" as to the potential and actual impacts of transportation to and storage at a repository for high-level radioactive waste and spent nuclear fuel less than 100 miles from Las Vegas, Nevada. Nearly 3,000 community indicators are tracked on a monthly basis and reported quarterly, with indices divided into categories of demographics, fiscal, economic, environmental, public health, and public safety. An annual community survey conducted as part of the monitoring program serves to "ground truth" the assumptions, data, and measures of progress. The information contained in this internet based system (www.monitoringprogram.com) is accessed by a variety of public and private sector groups including government agencies, financial institutions, academics, industry stakeholders, and private citizens in Nevada, across the USA, and in over 100 countries worldwide. Over time, groups outside of the nuclear waste program began to recognize the value in the data being collected and made available on the website. Clark County officials have since adopted the monitoring program as a useful tool for purposes of growth management and sustainability initiatives. Along with a discussion on the evolution of this tool in Clark County, the paper will benchmark Clark County's monitoring program against other similar efforts to monitor and measure indicators within the context of sustainability initiatives.
\end{abstract}

Keywords: community indicators, monitoring program, early warning system, sustainability, growth management, tourism, impact assessment, radioactive waste, transportation, indices, demographics, fiscal, economic, public health, public safety, environmental, community survey. 


\section{Background and introduction}

Until recently, Clark County, Nevada has maintained one of the highest growth rates in the United States for the past two decades. Fueling this sustained growth of more than 5,000 residents per month has been its tourist-based economy. Home to the world-famous "Las Vegas Strip," Clark County provides a unique mix of urban and rural communities and lifestyles. Of 8,060 square miles in land area, more than $90 \%$ of Clark County is rural in character. For the first time in two decades, however, Clark County has experienced an actual decline in population of $1 \%$ over the past year, down from a peak of 2 million (Clark County [1]). Further, Clark County is experiencing a significant decline in tourism, residential and commercial construction, and jobs. Clark County leads the nation in home mortgage foreclosures, unemployment stands at $10 \%$, and business bankruptcy is occurring at record levels (Clark County Monitoring Program [2]). Banking institutions, investments firms, and large corporate entities look to Clark County for a multitude of opportunities, and community indicators provide them with strong clues as to the health and stability of the region's economy, as well as the strength of the region's physical and social infrastructure. Key economic, environmental, demographic, and public health and safety indicators which provide insight into the sustainability of Clark County as a region, community, and political jurisdiction have shifted dramatically over the past two years (Clark County Monitoring Program [2]).

This paper will focus on the Clark County Monitoring Program, and how the community indicators monitored within the program have successfully served as an "early warning" of changing conditions, an analysis tool, and a support for decision making by policy makers and elected officials, both in times of economic upswing and downturn. Community indicators provide an essential framework for data collection and assessment, and this paper will provide examples for how community indicators can add value and substance to the ongoing dialog and decision making within the context of community sustainability.

\section{Overview and evolution of the Monitoring Program}

The objective of the Clark County Monitoring Program is to establish a measurable baseline to track community impacts over time, and from which impacts might be measured at a later date. This integrated community indicators program was developed to track, assess, and report indicators related to economic, fiscal and social factors, public health and safety, community wellbeing, and environmental issues. The primary impetus for the program was to establish a means of collecting data, and measuring and monitoring impacts over time associated with the transportation to, and operation of, a repository for highlevel radioactive waste and spent nuclear fuel about 90 miles away from Las Vegas, in Nye County, Nevada. (Clark County Monitoring Program [2].)

Since the initial implementation, the site was expanded to include rural community indicators in 2005, and in 2006 to include all of the cities within 
Clark County into the monitoring program in an effort to track municipal-level indicators (Clark County Monitoring Program [2]). The information contained in this internet based system is accessed by a variety of public and private sector groups including government agencies, financial institutions, academics, industry stakeholders, and private citizens in Nevada, across the USA, and in over 100 countries worldwide. Over time, groups outside of the nuclear waste program began to recognize the value in the data being collected and made available on the website. The number of indicators tracked in this unique, internet-based system has expanded from 800 to nearly 3,000, and many of the indicators are enhanced by GIS-based data and maps.

\subsection{Process and program elements}

The Clark County Monitoring Program is an integrated process composed of four key elements: visioning, planning, assessment, and implementation. In visioning, monitoring data is used to establish key relationships and measure key trends. In planning, monitoring data is used to establish a goal, determine outcome objectives, evaluate alternatives, and assess alternative strategies. In assessment, the program is used to determine strategy effectiveness, effects of outside influence, anticipated consequences and resulting impact. In implementation, the monitoring program is used to establish and track benchmarks, track changes, and identify causalities. Implementation of the monitoring program required six key steps: Identification of key issues and trends, review of departmental strategic plans, interviews with agency personnel, review and pilot testing, and final development of the indicators using agency data and consensus. The Clark County Monitoring Program is updated monthly, quarterly, annually, or as appropriate depending on the indicator. Quarterly reports are issued to key stakeholders, and special reports can be created on request. Quarterly reports are available in paper copy as well as on the website itself (Clark County Monitoring Program [2]).

\subsection{Monitoring program includes a broad spectrum of indicators}

The Clark County Monitoring Program tracks economic, fiscal, demographic, environmental, and public health and safety indicators. Economic indicators include residential and commercial real estate, vacant land and development, employment, income, spending, and tourism. Fiscal indicators include budget, taxes, tax climate, revenues, and spending. Demographics indicators include a community diversity profile, population, education, transportation, and state rankings. Environmental indicators track changes in biosphere, energy, water, and toxics. Finally, public health and safety indicators include police and fire statistics, prison population, health care, and wellness. These indicators can come from national, state, regional, and local sources, and include both performance and outcome measures. Stakeholder and community surveys serve to "ground truth" indicator data collected at the agency level (Clark County Monitoring Program [2]). 


\subsection{Community survey and stakeholder outreach}

Community or citizen surveys are a common tool used by local governments like Clark County to assess the public's views about the services provided. Surveys can be used to garner feedback on programs and services, and to demonstrate a desire for accountability and transparency in government service. Citizen surveys are commonly used when measurements of outcomes or performance are otherwise difficult to obtain. It is important to recognize that the public's experiences with government services and perceptions of success or failure influence how they judge government performance overall (Van Ryzin et al. [3]).

Clark County has conducted a number of surveys as a part of the Community Indicators Monitoring Program. One survey specific to the business community was conducted in 2007, and bi-annual or annual community surveys of the general public have been conducted since 2006. The community survey methodology consists of a random telephone survey of residents across the Las Vegas Valley. The survey sample size is 600 , out of a population of 1.9 million residents. Survey takers spend approximately 20 minutes per phone call covering approximately 135 questions. Some of the survey questions relate specifically to public opinions regarding the siting of a high-level radioactive waste repository near Las Vegas, but most of the questions are more general quality-of-life and government service questions. The questions are divided into sections, and are designed to garner both the relative importance as well as the perceived performance of a particular program or service. All questions are linked to the indicators tracked through the monitoring system. The survey results are collated, analyzed and reported back to Clark County officials. The survey results are also stratified according to the five municipalities within Clark County's geographic area. The survey results are used for reporting performance as a public information tool, as well as department and agency level strategic planning and decision making. The survey results specific to the nuclear waste repository are used to update impact assessment reports, as appropriate.

\subsection{Evolution of the Monitoring Program}

Subsequent to the implementation of the Clark County Monitoring Program, two notable Clark County efforts have been able to take advantage of the publicly available web based data and reports and adopt them for their own use. First, in 2006, the Clark County Growth Task Force adopted the monitoring program as a strategy and tool for measuring progress of its growth management initiatives. More recently, the Clark County Eco-County initiative, which focuses on various elements of sustainability, including organizational efficiency and energy conservation, has identified the Monitoring Program as a useful tool for measuring progress and public outreach and education.

\section{Sustainability indicators}

Indicators which measure sustainability, or "quality of life" in a community, extend beyond measurement, analysis and reporting of progress, or lack thereof 
within the context of specific, individual indices. Communities seeking to achieve and maintain sustainability examine what has become known as the "triple bottom line" consisting of three interrelated components which shape a sustainable community framework: society, environment, and economy. Effective sustainability indicators "tell the story" by highlighting linkages between or gaps in the social, economic, and environmental health of a community. When these three components are viewed as separate, unrelated parts of a community, problems are also viewed and addressed in an isolated fashion. Understanding the interrelationship between the three elements of sustainability and the strength of their links is key, as it is within those linkages that an appropriate level of tension and balance within the community is achieved.

Developing meaningful sustainability indicators requires thinking beyond the traditional economic (Gross Domestic Product), societal (crime rate) or environmental (air quality) indicator in order to achieve an integrated, long-term view of a community's health and wellbeing. The most effective singular or multidimensional indicators are those that provide an integrated, "big picture" view. It must also be recognized that sustainability indicators must be those most relevant to a particular community. In the case where a community wishes to sustain its good health and vibrancy, indicators can provide an "early warning" of negative trends. In a struggling community, indicators can provide for focusing scarce resources for most effective improvements. In all cases, indicates should serve as a basis for ongoing dialog toward a shared vision for the community (Sustainable Measures [4]).

\section{Examples of sustainability indicator programs}

\subsection{Glendale, Arizona example}

Consequent to the development and implementation of the Clark County Monitoring Program, Urban Environmental Research, LLC was commissioned to assist the City of Glendale, Arizona in the development of a neighborhood assessment tool as a part of their 5-year Neighborhood Revitalization Plan. As part of this plan, the need for a dynamic physical assessment tool for the city's neighborhoods was recognized. The intent of this tool (currently under development) is to measure and quantify variances in physical condition of neighborhoods that could be used to strategically guide the planning objectives and revitalization efforts for the city. The end result is envisioned to be a Neighborhood Indicator System (NIS) built off a robust database that will complement Glendale's existing GIS information tool (http:/gis.glendaleaz.com/NPP_GIS/). While the overall scope of the Glendale NIS is much narrower than in Clark County, with a strictly designed outcome specific to physical assessments (including, but not limited to: structural appearance, street conditions) and their representation alone, it is discussed here in an effort to highlight key issues that remain common to indicator programs regardless of their scale and purpose. 
Although the underlying purpose that led to the inception of Glendale NIS was significantly disparate from that of Clark County- (Glendale NIS is targeted specifically to be a physical conditions assessment and education tool while Clark County was conceived as an umbrella program across sectors and jurisdictions for predicting Yucca Mountain impacts and assess growth), the development process for both programs share certain similarities. Similar to the process employed for Clark County, the Glendale NIS went through the process of: 1) Identification of key issues and trends, 2) Review of Departmental Strategic plans, 3) Interviews with representatives from Glendale city Departments, agencies and programs, 4) Analysis of interview findings, and 5) Short listing of indicators based on financial resources and data availability.

Basic information to assess needs was gathered during interviews with over twenty-six individuals representing sixteen city departments and programs. To supplement this effort, a detailed literature review was conducted to understand and assimilate similar efforts for indicator programs across the country. As a result, a comprehensive list of indicators was created for the city staff and its partners from which to choose. This list was further supplemented by indicators that could be assembled with little to no financial investment by utilizing existing national and regional sources such as United States Census Bureau and the Maricopa County Assessor's office. It should be reiterated at this point that since Glendale NIS is being designed to assist neighborhood improvement efforts, the scale at which indicators are perceived to be monitored is significantly different than Clark County. While the strength of Clark County's program lies in the diversity of its indicators (ranging from economic to environmental to public health and safety), the future success of Glendale is predicted to be in its ability to track and monitor changes in housing conditions at the census tract level. The section below discusses the challenges and limitations encountered when a program is directed towards a scale-specific end result. For the purposes of this paper, scale (in the context of monitoring programs) is defined as the geographic boundary represented by the indicators. Depending on data availability and end use, indicators may be monitored at the regional scale (state, MSA), jurisdiction scale (city, township), or local/ neighborhood scale, such as zip code, census tract, census block, for example (Urban Environmental Research [5]).

\subsubsection{Design and implementation: key issues}

The following are some notable observations regarding opportunities, challenges, and lessons learned presented by the key elements used in the development and implementation of the Glendale NIS project.

4.1.1.1 Scale Probably the single most important factor that strings together the gamut of indicators within any monitoring program, enhances their individual values by allowing comparison, and makes them utilizable for their conceived purpose is the scale at which they are measured. For example, if in the initial planning process, a need was found to monitor regional growth and compare it to the national and global picture then it would be time-consuming and redundant 
to look for data at the street or neighborhood scale. Conversely, if the final goal of a program is to compare and measure physical condition of structures across neighborhoods (like in the case of Glendale NIS) then to even consider regionalscale indicators such as tax rates would defy the original intent and not be of a significant value for establishing educated and methodical planning guidelines.

Generally speaking, it is always easier to 'roll-up' the scale from a micro scale (such as street level) to a larger scale (such as district or city level). On the other hand, it is nearly impossible to pinpoint a specific geographic area associated with the highest/ lowest value of an indicator if the indicator has been originally measured for a larger boundary. While a 'bottom-up' approach may not be feasible for all scenarios depending on time and resource availability, for secondary source data it is always more prudent to seek data at the smallest available scale so as to preserve maximum possible spatial detail embedded within the data. In case of Glendale NIS, data is collected at the scale of the individual dwelling unit and rolled up to the census tract scale which allows for maximizing the choices during the design of the indicator system. Census tract was chosen as the preferred scale for Glendale NIS because due to the geographic nature of the city of Glendale, the geographic boundary of most census tracts of the city is defined by major streets. This facilitates ease of understanding of the scale for the local citizen (who may not recognize book numbers or voting precincts). While for physical condition assessment, this choice is fairly straightforward, it can be more complicated if the program is required to monitor data across various sectors (such as economic and public safety). As in the case of CCMP, this can lead to inconsistencies of scale and pose a problem for deriving cross-sector indices.

Considering that most indicator programs are initiated by units of local government, one of the challenges that they constantly face regarding issues of scale is the political ramifications that come from identifying specific local areas as being more problematic than others. Such discrimination can have a direct impact on citizen's perception and lead to an adverse effect on property values, detract job seekers (such as school teachers), or drive away businesses, thus triggering a downward spiral that can actually make these areas worse than before the program was put in place- and hence negating the very purpose of the program. A possible solution can be derived by allowing certain details of the indicators to be available only to city officials/ planners by setting up password protections on public databases such as web addresses. Nevertheless, reaching that point in a program requires substantial facilitation efforts in order to build up inter-agency trust and understanding.

4.1.1.2 Metrics Metrics act as a helpful tool for simplifying (and often combining) number-intensive indicators into a quick-reference visual picture that is usually best presented using mapping tools such as Geographic Information Systems. The greatest advantage of using metrics (or ratings- their numeric equivalent) is that they can facilitate combining unrelated indicators into a single variable for an overall score for that geographic boundary, which can then be easily translated into a color-coded visual. These are especially useful for 
presenting to large audiences or for a preliminary identification of hotspots that require further analysis. At the same time, they can lead to a reductionist perspective of the overall picture and should be used with caution and awareness of the details that lie behind their scoring during decision-making. The methodology used for deriving a rating/metric system is another challenge faced in the design of indicator programs. Some common methods include, but are not limited to: Z-score rating model (the average city value of an indicator is the benchmark), Percentage-rating models (based on a percentage range that a particular indicator falls within, in relation to the city average), Perception-based rating models (each community rates itself on a common scale, such as Likert scale), simple Numeric Comparison methods (using commonly known visual tools such as bar charts, pies that compare numeric values of geographic areas against each other/ nation/ region without any data normalization). While each of these methods embodies its own set of challenges and limitations within its design, details of these are not discussed here due to space limitation. However, the most common limitation is the tendency of a methodology to become too introverted, for example in models where city averages are used as benchmarks against which to compare other areas, a real sense of where the entire city stands in comparison to national or global Quality of Life standards can be lost.

4.1.1.3 Information gathering/data availability The backbone of any indicator program lies in the quality and regular availability of the data that informs the indicators. One of the keys to a successful design process is to determine the balance between 1) Available resources (financial, personnel, time), 2) Need for primary data generation and, 3) Utilization of secondary data sources. Contrary to general perception, a program designed using data generated specifically for the program may not be successful in the long run if it lacks the ability to sustain its data source over time. Even the most relevant indicator loses its value once the data becomes significantly outdated with no means to refresh the information to a point where it can be considered a reasonably accurate estimate of the community's current conditions. Glendale NIS is in the process of establishing a system where a combination of volunteer organizations and the regional university programs can work together to process, maintain and monitor data collected by the city consultants with the use of minimum financial resources.

4.1.1.4 Community involvement An often overlooked aspect of indicator programs is ensuring regular community participation in the development as well as everyday operations so as to incorporate locally relevant issues and to prioritize action plans based on citizen's choices. Charrettes, community workshops and public information tools such as the Internet are common choices for community outreach. If the agency undertaking the indicator program has a well-established outreach network within the community used for other programs, this resource should be tapped into for furthering the program. To ensure information sharing with the community, the Glendale NIS will tie in to the existing neighborhood information tools available through the city's GIS web application (City of Glendale [6]). 


\subsection{Maricopa County, Arizona example}

Maricopa County, Arizona is the most urban of Arizona's county's, and similar in size, topography, and population to Clark County, Nevada. Both Maricopa and Clark have similar resource management issues, with both having a dry, desert climate and decades of explosive population growth with fairly recent histories and evolutions as population centers for their respective states. The similarities are so marked, that both counties regularly are compared and benchmark against each other.

While not a sustainability indicators program in the conventional sense, Maricopa County's "Managing for Results" program includes a wide array of indicators, which taken together, can be considered sustainability indicators. The Maricopa County Board of Supervisors identified seven strategic priorities under which a number of community indicators are tracked. These priorities are Safe Communities, Public Health, regional Leadership, Sustainable Development, Fiscal Strength, Quality Workforce, and Citizen Satisfaction. It should be noted that the "Sustainable Development" strategic priority focuses on mainly environmental issues such as air quality, parks and open space, and energy conservation. The strategic priorities provide a framework for tracking, analyzing and reporting community well being and public perceptions. Public perceptions are verified through a community survey similar to that conducted by Clark County as part of its monitoring program. The key difference between the two surveys is that Maricopa County does not evaluate or correlate importance of a particular program or service against the citizen's level of satisfaction with that program or service (Maricopa County Annual Report of Community Indicators [7]).

\subsection{Jacksonville, Florida example}

The roots of Jacksonville, Florida's Quality Indicators for Progress extend back over three decades. This program provides valuable insight into how to build and maintain a successful sustainability indicators program. Jacksonville is the first city in the USA to have developed and implemented a method for measuring and monitoring quality of life within a community. The Jacksonville model takes into account nine elements within which indicators were established: economy, education, public safety, health, natural environment, social environment, politics/government, mobility, and culture/recreation. As was the case in the Clark County program, the Jacksonville program leaders recognized that one of the most important steps to establishing a successful indicators program is selection of the indicators themselves. The criteria for selecting indicators in the Jacksonville model included validity, availability, reliability, responsiveness, understandability, policy relevance, and representativeness (Chambers [8]). Other similarities to the Clark County program include a citizen survey conducted by telephone, and a process for refining, adding, and removing indicators in response to changing conditions. 


\section{Lessons learned and conclusion}

A number of common themes can be derived from research into community and sustainability indicators. First and foremost, a shared vision for the community is an important fundamental. Next, it is clear that transparency and accessibility of data and reports are required for a successful indicators program. Effective communication and ongoing dialog between and among stakeholders and decision makers is also vital. System flexibility to accommodate changing conditions in organizations in within communities also adds value. Finally, participants in sustainability indicator programs also recognize that such programs cannot be all things to all people, as a significant commitment of time, resources, and public education is required to ensure successful implementation and maintenance of the program.

\section{References}

[1] Clark County, retrieved March 30, 2009, www.accessclarkcounty.com

[2] Clark County Monitoring Program, retrieved March 30, 2009, www.monitoringprogram.com

[3] G. Van Ryzin, et al. Public Administration Review, March/April 2008, Volume 68, No. 2, Measuring Street Cleanliness: A Comparison of New York City's Scorecard and results from a Citizen Survey, p. 295-296

[4] Sustainable Measures, - What is sustainability anyway? Retrieved April 1, 2009

[5] Urban Environmental Research, Draft Neighborhood Indicator System, City of Glendale Phase 1 Report, Prepared for the City of Glendale Community Partnerships Department, April 2008

[6] Glendale Neighborhood GIS Website, http://gis.glendaleaz.com/NPP_GIS Default.aspx. rtrieved April 9, 2009

[7] Maricopa County Annual Report of Community Indicators, retrieved April 9, 2009

[8] Jacksonville Community Council, Inc., 1994, Quality Indicators for Progress: A Guide to Community Quality of Life Assessments, M. Chambers, p. 32 